\title{
Exercise training in pulmonary arterial hypertension
}

\author{
Laura Adelaide Dalla Vecchia, Maurizio Bussotti
}

Department of Cardiology, Istituti Clinici Scientifici Maugeri SpA SB, Istituto di Milano-IRCCS, Milan, Italy

Contributions: (I) Conception and design: All authors; (II) Administrative support: All authors; (III) Provision of study materials or patients: All authors; (IV) Collection and assembly of data: All authors; (V) Data analysis and interpretation: All authors; (VI) Manuscript writing: All authors; (VII) Final approval of manuscript: All authors.

Correspondence to: Laura Adelaide Dalla Vecchia. Department of Cardiology, IRCCS, Istituti Clinici Scientifici Maugeri, via Camaldoli 64, 20138 Milano, Italy. Email: laura.dallavecchia@icsmaugeri.it.

\begin{abstract}
Pulmonary arterial hypertension (PAH) is characterized by a continuous increase in precapillary pulmonary vascular resistance (PVR) with a progressive reduction of cardiac output (CO). Similar to what occurs in left heart failure (HF), this represents the initial phase of a syndrome characterized by the progressive development of dyspnea and fatigue with increasing deterioration of exercise tolerance. Although the therapies introduced in the last two decades have determined a significant improvement of the clinical conditions of PAH patients, they have a little impact on exercise capacity and prognosis. However, as previously demonstrated for HF, recent pilot studies have reported that physical and respiratory rehabilitation may have a specific role in the management of PAH. Despite potential risks, so far all studies agree that exercise training (ET) improves exercise capacity, quality of life (QoL), muscle function and pulmonary circulation. We will review the pathophysiological mechanisms underlying the functional incompetence of PAH patients, the effects of ET on clinical and functional parameters, the selection criteria for inclusion of patients in a training program, the suggested monitoring of beneficial effects or possible side effects induced by ET. Finally, we discuss of the possible exercise induced amelioration of prognosis in PAH.
\end{abstract}

Keywords: Exercise; training; pulmonary hypertension (PH)

Submitted Jan 01, 2018. Accepted for publication Jan 17, 2018.

doi: $10.21037 /$ jtd.2018.01.90

View this article at: http://dx.doi.org/10.21037/jtd.2018.01.90

\section{Background}

Pulmonary arterial hypertension (PAH) consists of a continuous raise of pre-capillary pulmonary vascular resistance (PVR). PAH is defined by a resting mean pulmonary artery pressure (PAP) $\geq 25 \mathrm{mmHg}$, a wedge pressure $<15 \mathrm{mmHg}$ and a PVR $>3$ Wood Units, all measured by right heart catheterization, in the absence of other causes of pre-capillary pulmonary hypertension $(\mathrm{PH})$, namely lung diseases, chronic pulmonary thromboembolism or other rare diseases (1). The disproportionate afterload the right ventricle has to face is at the origin of its failure, followed by the reduction of cardiac output (CO), at first during exercise and then even at rest (Figure 1) (2). Usually, the early stages of $\mathrm{PAH}$ are free from symptoms, as the right heart initially manages to maintain an adequate CO.
Nevertheless, as the disease progresses, patients experience worsening dyspnea and fatigue, sometimes followed by syncope and angina. Unlike those forms of $\mathrm{PH}$, due to left heart failure (HF) or lung disease (Group 2 and 3 of $\mathrm{PH}$ Classification) (3), PAH is caused by a primary complex pathology of the pulmonary arterioles.

Although the therapies introduced in the last two decades have determined a meaningful improvement of the prognosis in PAH patients, they have not demonstrated any influence on the underlying causes of the disease. Although the use of PAH-targeted treatments as well as supporting therapies, such as anticoagulation and diuretics, have demonstrated an improvement of the symptoms and a slowdown of the progression of the disease, both mortality and morbidity from PAH remain high (4-9). Furthermore, patients with $\mathrm{PAH}$ often develop asthenia, fatigue, shortness 


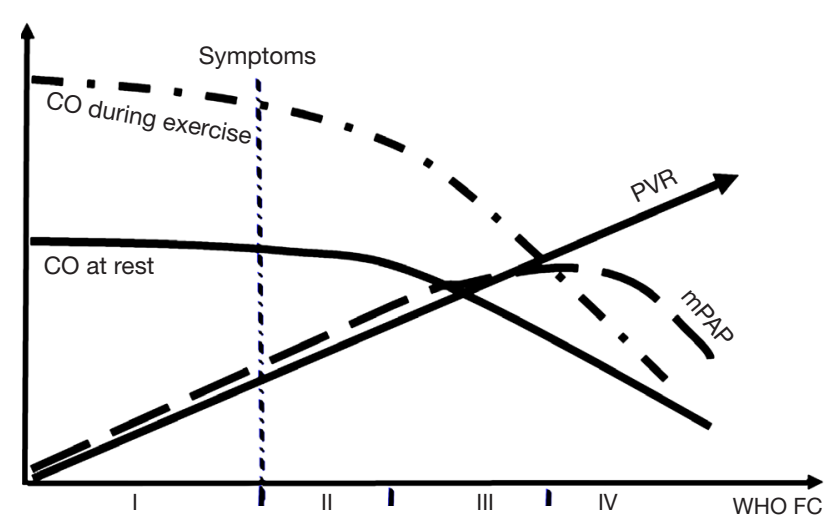

Figure 1 Pulmonary arterial hypertension: a progressive disease. This scheme represents the progressive clinical course of pulmonary artery hypertension coupled to hemodynamic changes over years. CO, cardiac output; WHO, World Health Organization; FC, functional class; mPAP, mean pulmonary artery pressure; PVR, pulmonary vascular resistances.

of breath paired up with an impairment of exercise capacity and quality of life (QoL). As it occurs in HF, muscular cachexia of both peripheral and respiratory muscles, leading to functional deconditioning are usual findings in PAH. Moreover, PAH may concern young, working, and fertile people, who may undergo severe psychological effects; thus patients often show anxiety, depression, hopelessness, and panic attacks. Analogously to HF, whose clinical guidelines suggest that exercise training (ET) is auxiliar to medical therapy, physical and respiratory rehabilitation may have a specific role in the management of PAH. Recent pilot studies have referred the favorable effects of ET in PAH despite its presumed risks. However, ET was not mentioned in the previous guidelines for the treatment of $\mathrm{PAH}$, since it was believed irrelevant considering the poor survival rate of the disease together with the fear of a more rapid worsening of the right heart function. The first randomized controlled study evaluating the impact of ET on PAH dates back to 2006. It indeed showed an improvement of exercise capacity and QoL (10). Further uncontrolled trials that investigated the results of a light-dose exercise and respiratory training in PH secondary to several etiologies showed an improvement of exercise capacity, QoL, muscle function, muscular capillarization and pulmonary circulation $(4,5,8,11-15)$. A recent randomized controlled study conducted in patients with severe chronic thromboembolic $\mathrm{PH}$ demonstrated an improvement in prognostic parameters (16).

The beneficial effects of ET have been ultimately recognized, so that the rehabilitation program received a $1 \mathrm{~A}$ recommendation at the $\mathrm{PH}$ world symposium in Nice in 2013 (17). This decision was mainly based on three randomized controlled trials that investigated a limited number of patients $(10,18,19)$. However, the clinical features that make a patient with $\mathrm{PAH}$ eligible to ET have not yet precisely defined.

All studies included clinically stable patients, in World Health Organization (WHO) Functional Class (FC) II-III and on optimal medical therapies, with no recent history of syncope on exertion.

It is reasonable that WHO FC I patients might also beneficially participate to an ET program, despite the few data. A major degree of uncertainty outlines the appropriateness of ET for WHO FC IV patients, although even these patients might be suitable for a safe and beneficial ET.

Hereby, we will review (I) the main pathophysiological mechanisms at the origin of the functional exercise incompetence observed in PAH; (II) the clinical and functional variables usually modified by a tailored ET program; (III) the selection criteria and how to perform the monitoring of the beneficial effects as well as the side effects; (IV) the rehabilitation protocols currently used and their possible prognostic impact.

Our wish is that this compendium may contribute to the diffusion and implementation of exercise programs for patients with $\mathrm{PAH}$, as well as incentive to collect and publish data to contribute to a better understanding of exercise-related advantages in PAH.

\section{The pathophysiological basis of functional deconditioning in PAH}

Asthenia, fatigue and shortness of breath represent the most frequent symptoms in a patient with PAH (1). The etiological factors for these symptoms have both central and peripheral origin (Figure 2). Central functional deconditioning is the result of the combined right ventricular (RV) systolic and left ventricular (LV) diastolic impairment so that an inadequate $\mathrm{CO}$ is determined by a stiffened pulmonary bed on one hand, and the reduced LV filling secondary to the pressure overload determined by the left septal displacement on the other hand. Peripheral functional deconditioning in patients with $\mathrm{PAH}$ shows similarities with what occurs in chronic HF. In fact, chronic hypoperfusion determines a detrimental effect on the muscular skeletal mass of the limbs and of the 


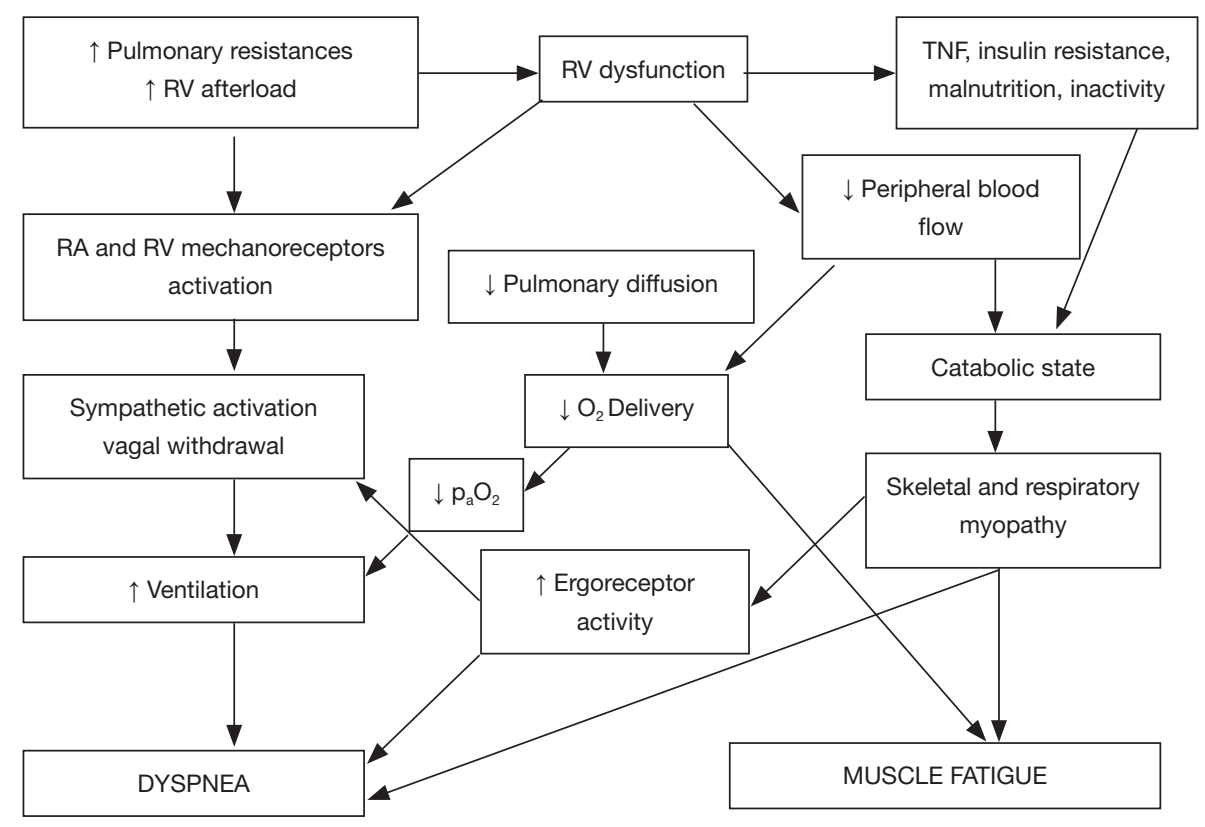

Figure 2 The pathophysiological cascade leading to symptoms in pulmonary arterial hypertension. In this syndrome the clinical picture is justified by a combination of cardiorespiratory, autonomic nervous system and muscular abnormalities consequent to the initial increase of PVRs. $\uparrow$, increased; $\downarrow$, decreased. RA, right atrium; RV, right ventricle; $\mathrm{p}_{\mathrm{a}} \mathrm{O}_{2}, \mathrm{O}_{2}$ arterial pressure; PVR, pulmonary vascular resistance; TNF, tumor necrosis factor.

respiratory muscles. The weakening of the inspiratory muscle mass in PAH has been suggested by recent studies that demonstrated markedly reduced volitionally assessed maximal inspiratory mouth pressures and non-volitionally assessed trans-diaphragmatic pressures in patients with PAH compared with control subjects $(20,21)$. Thus, these patients are constrained to fulfill a higher ventilator demand through a weaker inspiratory capability (22). Inspiratory muscles are impaired to generate force, and this causes early fatigue and dyspnea (23).

Hypoxemia, increased lung perfusion/ventilation mismatch and catecholamine overdrive determine the typical hyperventilatory pattern in $\mathrm{PAH}$ and subsequently hypocapnia. In PAH, hypocapnia is a sign of a higher ventilatory demand provided by the inspiratory muscles, moreover it has also been recently recognized as a marker of poor prognosis (24). Both the chronic mechanical overload of the inspiratory muscles, secondary to hyperventilation, and their chronic hypoperfusion prompt structural changes in their fibre-cells, resemble those ascertained in patients affected by HF.

The observation of a reversed conversion from fast to slow myosin isoforms, a typical pattern associated with some myopathies, of a cross-sectional muscle fiber reduction, and of a depressed oxidative capacity (in turn depending by the reduced volume of mitochondria, surface of the mitochondrial cristae, and number of mitochondrial enzymes involved in the oxidative metabolism) is common to what has been demonstrated in the states of prolonged inactivity (23).

So far, there is no single interpretation that may unify the pathophysiological mechanism underlying muscular involvement in PAH. Inflammatory activation is considered primarily implicated. Pro-inflammatory cytokines have a noxious effect on skeletal muscle because they harm the activity of contractile proteins (25) and prompt their proteolysis (26). Indeed, high levels of circulating proinflammatory mediators, such as interleukins and tumor necrosis factor (TNF)- $\alpha$, were detected in both PAH animal models and patients (27) and were correlated with poor prognosis (28).

A further underlying mechanism might involve the inhibition of hormonal/anabolic pathways, essential for promoting protein synthesis and preserving muscular protein from degradation (29). In $\mathrm{PAH}$, the most explored anabolic axis is the insulin signaling. In fact, an increased prevalence of insulin resistance has been recently reported (30). 
It is also probable that chronic hypoxemia plays a role in muscle dysfunction (31). Skeletal muscle microcirculation appears to be altered as inferred by the low $\mathrm{O}_{2}$ saturation at the tissue level, quantified by a near-infrared spectroscopy technique (32). In addition, an altered microvascular $\mathrm{O}_{2}$ delivery-to-utilization rate, which in turn slows the rate of adaptation to aerobic metabolism was demonstrated in women with PAH (33). Indeed, patients with PAH display the so-called Warburg effect, i.e., the aforementioned aerobic/glycolytic switch. Muscular biopsies of $\mathrm{PAH}$ patients in WHO FC II-III show a higher phosphofructokinase/3hydroxyacyl-CoA-dehydrogenase proportion suggestive of a greater tendency to anaerobic rather than aerobic metabolism (34).

All these defects are predominantly present in the diaphragm, which is the most important inspiratory muscle. Other authors argue that the weakness of the diaphragm present in PAH might represent a specific local process $(35,36)$, that is different from the peripheral skeletal muscle abnormalities. According to this latter theory, although it has not been yet demonstrated, in patients with PAH, as well as in HF patients (37), the disorders of the metabolism of the muscle cell might lead to a hyperactivation of the great number of the metabolic receptors present in the diaphragm with a subsequent adrenergic overdrive.

Furthermore, acute activation of the sympathetic nervous system occurs as an adaptive response, targeted to re-establish or maintain $\mathrm{CO}$ and systemic arterial pressure levels. However, long-term sympathetic hyperactivity has deleterious effects and accelerates the disease progression $(38,39)$. In addition to the increased sympathetic activity, a decrease in parasympathetic activity has also been observed in PAH (40). The autonomic imbalance could be associated to baroreflex sensitivity impairment as well as exercise intolerance and ventilatory inefficiency of PAH patients, again similarly to HF patients $(38,39)$.

\section{Efficacy of training in PAH on functional capacity, QoL, survival}

ET may have a number of potential therapeutic targets. The precise mechanism through which PAH patients benefit from exercise-based interventions remains unclear.

Even 2015 ESC/ERS guidelines highlighted the lack of a clear theory to explain how ET contributes to the improvement of symptoms and functional capacity, as well as its favorable effects on outcomes (41). For this reason, their recommendation for ET remained in class $2 \mathrm{~A}$ with a level of evidence B. However, clinical evidence in support of ET use in $\mathrm{PAH}$ is growing, thus requiring an effort to elucidate the benefits of ET in these patients. A recent study has focused on the role of $\mathrm{H}_{2} \mathrm{O}_{2}$-induced angiogenesis as a possible mechanism to explain the increased pulmonary vascular reserve during exercise (42). It has been demonstrated an increase of $\mathrm{H}_{2} \mathrm{O}_{2}$ in $\mathrm{PAH}$-trained animals (42). Aerobic ET also facilitated the expression of VEGF gene, and its positive correlation with Akt phosphorylation. This is in keeping with the known effect of ET in reducing the levels of monocytes and macrophages, as well as the expression of inflammatory genes in the pulmonary circulation, ultimately leading to an improvement of reactive oxygen species production and physiological angiogenesis (43).

Recently, it has been demonstrated that respiratory muscle training in HF rats is able to produce positive adaptations on lung and peripheral vascular nervous system, which are translated into better hemodynamic function and respiratory mechanic parameters (44). The changes observed in pressure response during chemoreflex activation were probably associated with a better sympatho-vagal balance, demonstrated by the attenuation of the sympathetic modulation together with an enhanced parasympathetic modulation after ET. Among the beneficial effects of regular exercise, an improvement in neural control of heart rate (HR) has been documented by studies analyzing the spectral analysis of HR variability in chronic HF patients: the clinical indices of cardiac vagal regulation and baroreflex sensitivity, that are depressed in patients with HF and carry a poor prognosis $(40,45)$, have been consistently improved by aerobic ET (46).

In PAH, as reported in HF, ET has all the credentials to improve endothelial dysfunction, muscular blood supply, peripheral $\mathrm{O}_{2}$ extraction, muscular strength, ventilatory efficiency, ventricular contractility, reduce adrenergic tone, increase vagal modulation, and restore baroreflex arterial sensitivity (47).

The clinical studies exploring the ET impact on PAH are only 16 , enrolling a total number of 413 patients (122 males and 291 females) with miscellaneous etiological forms of $\mathrm{PH}$, either idiopathic or secondary to congenital heart defects, chronic pulmonary thromboembolism, or connective tissue disorders (Table 1). Out of these 16 studies, three are randomized controlled trials, four are non-randomized clinical trials with control groups and nine are non-randomized prospective studies without 
Table 1 Baseline characteristics of studies exploring the effects of exercise training on patients with pulmonary arterial hypertension

\begin{tabular}{|c|c|c|c|c|c|c|}
\hline Author & Year & $\begin{array}{c}\text { Trained } \\
\text { patients \#, [F] }\end{array}$ & $\begin{array}{c}\text { Control } \\
\text { patients, }[\mathrm{F}]\end{array}$ & $\mathrm{PH}$ classes & ET protocol & Duration and follow-up \\
\hline \multicolumn{7}{|c|}{ Randomized control trial } \\
\hline Ley et al. & 2013 & $10[8]$ & $10[6]$ & $16 \mathrm{PAH}, 4$ СТEPH & $\begin{array}{c}\text { Bicycle, walking, dumbbell, } \\
\text { RT }\end{array}$ & 3 weeks/in-hospital \\
\hline Mereles et al. & 2006 & 15 [10] & $15[10]$ & 24 PAH, 6 СТEPH & $\begin{array}{c}\text { Bicycle, walking, dumbbell, } \\
\text { RT, MT }\end{array}$ & $\begin{array}{c}3 \text { weeks/in-hospital + } \\
12 \text { weeks/at home }\end{array}$ \\
\hline \multicolumn{7}{|c|}{ Observational control studies } \\
\hline Chan et al. & 2013 & $10[10]$ & $13[13]$ & $\mathrm{PAH}$ & Treadmill walking & $\begin{array}{l}10 \text { weeks/outpatient } \\
\text { rehabilitation clinic }\end{array}$ \\
\hline $\begin{array}{l}\text { Martinez- } \\
\text { Quintana et al. }\end{array}$ & 2010 & 4 [2] & $4[1]$ & CHD-PAH & $\begin{array}{c}\text { Bicycle, resistance, } \\
\text { educational lesson, HT }\end{array}$ & $\begin{array}{l}12 \text { weeks/outpatient } \\
\text { rehabilitation clinic }\end{array}$ \\
\hline Weinstein et al. & 2013 & $11[11]$ & $13[13]$ & $\mathrm{PAH}$ & Treadmill walking & $\begin{array}{l}10 \text { weeks/outpatient } \\
\text { rehabilitation clinic }\end{array}$ \\
\hline $\begin{array}{l}\text { Becker-Grunig } \\
\text { et al. }\end{array}$ & 2013 & $20[16]$ & - & - & Bicycle, dumbbell, RT, MT & $\begin{array}{c}3 \text { weeks/in-hospital + } \\
12 \text { weeks/at home }\end{array}$ \\
\hline Bussotti et al. & 2016 & $15[14]$ & - & $\mathrm{PAH}-\mathrm{CHD}$ & Bicycle, dumbbell, RT, MT & $\begin{array}{l}4 \text { weeks/outpatient } \\
\text { rehabilitation clinic }\end{array}$ \\
\hline De Man et al. & 2009 & 19 [15] & - & IPAH & $\begin{array}{c}\text { Bicycle, quadriceps strength, } \\
\text { endurance }\end{array}$ & $\begin{array}{l}12 \text { weeks/outpatient } \\
\text { rehabilitation clinic }\end{array}$ \\
\hline Inagaki et al. & 2014 & $8[8]$ & - & 8 CTEPH & $\begin{array}{l}\text { Walking exercise, lower and } \\
\text { upper-limb strength training, } \\
\text { respiratory exercises }\end{array}$ & 12 weeks/at home \\
\hline Mainguy et al. & 2010 & $5[4]$ & - & IPAH & Bicycle, dumbbell, RT, MT & $\begin{array}{c}3 \text { weeks/in-hospital + } \\
12 \text { weeks/at home }\end{array}$ \\
\hline Nagel et al. & 2012 & $35[16]$ & - & CTEPH & Bicycle, dumbbell, RT, MT & $\begin{array}{l}3 \text { weeks/in-hospital + } \\
12 \text { weeks/at home }\end{array}$ \\
\hline
\end{tabular}

\#, number. F, females; PAH, pulmonary arterial hypertension; CHD, congenital heart disease; CTD, connective tissue disease; CTEPH, chronic thromboembolic pulmonary hypertension; ET, exercise training; IPAH, idiopathic PAH; HT, home training; MT, mental training; RT, respiratory training. 
control groups. Finally, there are three case reports or case series (48).

Overall, the number of enrolled patients is quite small, ranging from 20 to 183 patients, mostly utilizing unstandardized combinations of aerobic and resistance training protocols.

Nine of these 16 studies exploited an association of supervised hospital-based and home-based ET programs. Besides, all these investigations have been carried out by the same group, i.e., Clinic Königstuhl in Heidelberg, since 2006. The training program consisted of various interventions, namely interval training ergometer, respiratory therapy, muscle training and mental gait training $(4,5,8,10,11,13,14,49)$.

The interval training allows performing an aerobic ET with a low cardio-circulatory stress. In patients with $\mathrm{HF}$, this training has been successfully implemented $(50,51)$. Interval training is conducted at a cycle ergometer, the first step consisting of 30 seconds (s) at a lower workload [0 to 10 Watts $(W)$ ], followed by an interval of $60 \mathrm{~s}$ at a higher load [20 to $35 \mathrm{~W}$ ]. This intensity corresponds to about $60-80 \%$ of the HR achieved during a baseline exercise test. Based on subject tolerance, the workload intensity is progressively increased up to $50 \mathrm{~W}$, maintaining a $\mathrm{HR} \leq 120 \mathrm{bpm}$, and an oxygen saturation $>85 \%$ (10). Five days per week subjects undergo resistance ET, i.e., 30 min of training with 500 to $1,000 \mathrm{~g}$ dumbbells, and respiratory training, i.e., 30 min of stretching, breathing techniques (e.g., pursed lip breathing), body perception, Yoga, and respiratory muscle strengthening exercises (10).

Resistance ET should follow a low-moderate resistance (50\% of 1 -repetition maximum)/high repetition (10-15 times) paradigm, while avoiding the Valsalva maneuver.

Respiratory therapy has been established in the rehabilitation of patients with lung disease for the last years $(52,53)$. The different techniques aim to improve ventilation, to strengthen the respiratory muscles, to mobilize the thorax and to enhance secretolysis (54).

In addition, subjects walk $60 \mathrm{~min}, 5$ days per week, accompanied by physiotherapists to accomplish the ability to perceive their personal limits over which an effort might become excessive or unsafe (10). Such training was adapted from mental imagery techniques used by sport psychologists in professional athletes. Mental imagery techniques have shown to improve physical and cognitive functions $(55,56)$.

Once the patients are discharged, they continue the same ET at home for 12 more weeks, following the instructions included in an individualized training booklet. Subjects are also taught to monitor their $\mathrm{HR}$ and $\mathrm{O}_{2}$ saturation during exercise. A physical therapist and/or physician monitor by phone home training progress at 2-week intervals (10).

A similar holistic approach seems to induce a positive effect on many targets, such as the RV function, pulmonary circulation, limbs musculature, respiratory muscles, chemoreceptors and baroreceptors. In our clinic for example, the patients follow sessions of respiratory ET that include slow breathing and muscular relaxation, aimed to decrease adrenergic hyperactivity and peripheral chemoreceptor activation, and to reduce dead space ventilation increasing ventilatory efficiency (57). Similarly, in patients with HF (58) and/or chronic pulmonary diseases (59), slow breathing has been shown to improve dyspnea, pulmonary gas exchange and exercise performance. In $\mathrm{HF}$ patients, inspiratory muscle training also decreases respiratory fatigue and increases exercise capacity (60). These results are effectively encouraging, as in all the studies ET seems to lead to numerous clinically relevant benefits: an overall improvement in QoL, WHO FC, peak oxygen consumption $\left(\mathrm{VO}_{2}\right)$ and achieved workload, exercise endurance, muscle strength and ambulation ability.

Different tools have been used to measure QoL, and regardless of the used algorithm, all studies evidenced an improvement of QoL (see next paragraph). In addition, an average improvement by one FC has been observed in some studies $(4,5,10,61)$.

Regarding the exercise endurance, a recent metaanalysis including 12 studies (2 randomized controlled trials, 4 observational controlled studies with control groups, and 6 observational studies without controls) has reported an increase in $\Delta 6$ min walking distance (6MWD) of $62.2 \mathrm{~m}(95 \%$ CI: 45.6 to $78.8, \mathrm{P}<0.0001)$ after 12 weeks of exercise (62).

Regarding follow-up evaluation with cardiopulmonary exercise test (CPET), the same meta-analysis indicated a major rise in peak $\mathrm{VO}_{2} / \mathrm{kg}$ by $1.3 \mathrm{~mL} / \mathrm{min} / \mathrm{kg}(95 \%$ CI: 0.8 to $1.9 ; \mathrm{P}<0.00001)$ after 3 weeks of $\mathrm{ET}$ and by $1.7 \mathrm{~mL} / \mathrm{min} / \mathrm{kg}(95 \% \mathrm{CI}: 1.1$ to $2.3 ; \mathrm{P}<0.00001)$ at 12 or 15 weeks versus baseline values (62). Workload was also incremented by $13.1 \mathrm{~W}$ (95\% CI: 8.9 to 17.4 ; $\mathrm{P}<0.0001)$ and by $17.0 \mathrm{~W}$ (95\% CI: 12.3 to $21.7 ; \mathrm{P}<0.0001)$ after 3 weeks and after 12-15 weeks of exercise, respectively (62). Our data also confirm improvements in functional capacity after a 4-week period of ET, with an improvement of the 6 MWD from $455 \pm 115$ to $487 \pm 120 \mathrm{~m}(+8 \%, \mathrm{P}<0.01)$, while workload at CPET raised from $73 \pm 22$ to $87 \pm 21 \mathrm{~W}$ $(\mathrm{P}<0.001)$ and peak $\mathrm{VO}_{2} / \mathrm{kg}$ raised from $17.3 \pm 4.2$ to $19.9 \pm 4.5 \mathrm{~mL} / \mathrm{kg} / \mathrm{min}(\mathrm{P}<0.001)(57)$ (Figure 3$)$. 


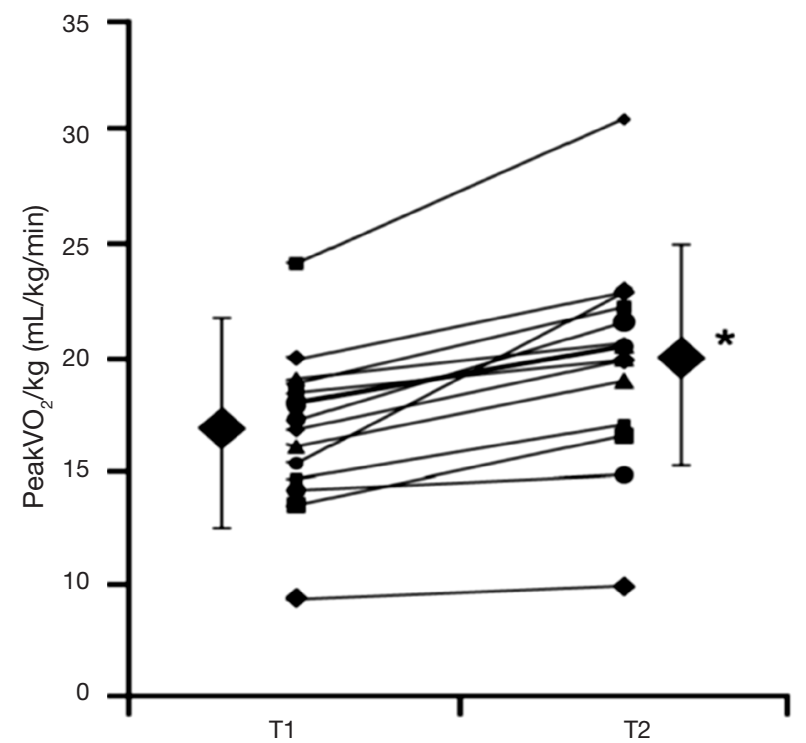

Figure 3 Evaluation of exercise training in PAH by means of a CPET. After 4 weeks of exercise training, peak $\mathrm{VO}_{2}$ raised from $17.3 \pm 4.2$ to $19.9 \pm 4.5 \mathrm{~mL} / \mathrm{kg} / \mathrm{min}\left({ }^{*} \mathrm{P}<0.001\right.$ ) (from Bussotti et al. 2017). Symbols represent changes of peak $\mathrm{VO}_{2}$ for each of the 15 patients enrolled in the study; larger black diamonds represent mean values \pm SD. T1, baseline; T2, after 4 weeks of training; PAH, pulmonary arterial hypertension; CPET, cardiopulmonary exercise test.

What could be responsible of such an improvement in functional performance remains however to be understood. A role of vasodilation of the pulmonary circulation might be advocated. Unfortunately, all but one of the clinical trials assessing exercise-induced changes of pulmonary arterial systolic pressure (PASP) by Doppler echocardiography failed to demonstrate a favorable change of this parameter (63).

Conversely, a study utilizing magnetic resonance imaging (MRI) found that ET improved lung blood volume and diminished peak flow velocity in pulmonary artery, supposing a vasodilatation of vessels of the pulmonary circuit (49).

The ability of aerobic ET to improve endotheliumdependent relaxation of pulmonary vessels in PAH patients has not been demonstrated, thus further investigations are required. Anyway, importantly, in patients with stable PAH, ET does not worsen pulmonary circulation or vessel wall characteristics (63).

Finally, we must underline that the REVEAL registry (64) showed that improvements in the FC corresponded to a better prognosis with a prolongation of life expectancy up to 3 years.

In addition, a study conducted over 58 patients with severe PAH on stable disease-targeted medication demonstrated that a program of exercise and respiratory training ( 3 weeks in hospital followed by $24 \pm 12$ months at home) improved QoL, exercise tolerance and survival, the latter being $100 \%$ and $95 \%$ at 1 and 2 years, respectively (4). A second study reported survival rates of $100 \%$ at 1 and 2 years, and of $73 \%$ at 3 years in patients with connective tissue disorder related-PAH, again receiving ET on top of optimal drug therapy (5). This survival was even higher than that documented by the REVEAL Registry for the subgroup with PAH secondary to connective tissue disease, where the survival was $93 \%$ at 1 year (65). One further study reported $100 \%$ transplantation-free survival rate after 1 year, and $93 \%$ after 2 years (11).

Overall these data suggest that ET provides survival benefits when used as an additional treatment intervention. Not surprisingly, ET is of growing interest in major cardiovascular disease guidelines $(66,67)$. In general, exercise can be considered a therapy in a number of cardiovascular disorders, in particular those associated with deconditioning. The therapeutic potential of restoring a proper cardiovascular sympatho-vagal modulation in these patients is very promising (68), although long-term followup of a larger study population is required to confirm definite survival benefits with ET.

\section{Depression, QoL and psychological support}

Patients with PAH face various life stress factors, such as physical disabilities, undefined outcome, contraindications to have a pregnancy, high cost of treatment, and unemployment. This whole undoubtedly determines a psychological burden, also affecting socialization $(69,70)$. In about $35 \%$ of $\mathrm{PAH}$ patients, these stressors lead to the development of mental disorders, such as anxiety, panic disorders and depression $(69,71,72)$.

These common disorders are closely related to the severity of symptoms and functional disability. The prevalence of major depression increases from $7.7 \%$ in WHO FC I patients to $45 \%$ in FC IV (69). Similarly, the prevalence of panic attacks increases up to $25 \%$ in $\mathrm{FC}$ IV. Mood disturbances affect QoL, although they do not increase mortality. To date, no difference in survival rates has been found between patients with no or mild mental disorders (where survival at 1-, 2- and 3-year was $97.4 \%$, $92.9 \%$ and $82.4 \%$, respectively) and those with moderate to 
severe mental disorders (where survival was 93.9\%, 90.2\% and $80.2 \%$, respectively) (73).

For these reasons, QoL should be considered one of the main goals of PAH treatment (74). In other words, new therapies should be tested in terms of survival as well as improvement of QoL.

Regrettably, mental ailments are still poorly recognized, consequently it is estimated that only $24.1 \%$ of PAH patients receive appropriate psychopharmacological or psychotherapeutic treatment (69). There is generally a poor psychosocial support for these patients. Therefore, counseling and psychosocial help should integrate treatment for PAH patients. Many studies have pointed out that the rehabilitation program, considered as add-on to medical therapy, can serve as an adjuvant to manage depression and anxiety in patients with $\mathrm{PAH}(5,8,10,11,18,57)$. For example, studies that utilized the non-disease specific Short Form36 (SF-36) to assess QoL showed that ET ameliorated physical and mental health items, as well as those of general health perception, vitality, and social functioning $(5,8)$, while, conversely, it lowered pain scores (11). Studies utilizing PAH-specific validated questionnaires, such as the Cambridge Pulmonary Hypertension Outcome Review (CAMPHOR) (75), documented a post-ET improvement in energy, dyspnea, and mood (18). ET also showed to decrease the fatigue perception, as revealed by the Fatigue Severity Scale, therefore increasing the amount of physical activity (19). A recent meta-analysis confirmed that ET improved QoL with relevant benefits on physical and social behavior (63).

In our clinical practice, during hospitalization, patients undergo 4-10 cognitive-behavioral sessions to facilitate the recognition of negative behavioral and/or thinking patterns that may worsen their feelings, and to develop the 'coping skills' directed to their symptoms and reactions. Patients also practice progressive muscle relaxation applied to specific muscular groups and Yoga exercises to improve deep and slow breathing (57). The goals of the psychological training are to handle emotional disturbances, to grow knowledge, awareness and acceptance of the illness, and to facilitate intrapersonal, interpersonal and occupational adaptation to their condition. Furthermore, the daily practice has taught us that mutual relationship among patients can improve their emotional state and social life.

\section{Side effects of ET}

The rapid deterioration of $\mathrm{RV}$ performance with its subsequent compromised hemodynamic effect, the occurrence of arrhythmias and syncope have always been considered the major risks of an exercise program in severe PAH $(2,41,76)$.

Actually, no study has reported an increased incidence of major side effects in PAH patients undergoing a personalized and monitored ET. In a recent data-report, Heidelberg's researchers concluded that only the $13.6 \%$ of their patients (25 out of 183 patients) had adverse events during an ET program administered over a 3-week inhospital stay. Severe adverse events, i.e., syncope/presyncope or ventricular arrhythmias, occurred only in $4.4 \%$ of the patients (13). Overall, respiratory infections and syncope/pre-syncope were reported more frequently. An acute respiratory infection forced the transitory suspension (1-2 weeks) of the training program in $7.6 \%$ of the patients. One patient complained of a single episode of slight hemoptysis. Two patients had a syncopal episode and six experienced a pre-syncope, all occurring several hours after the completion of the ET session. Episodes of self-limited supraventricular tachycardia were recorded in two patients while exercising (13). However, most patients tolerated the ET without side effects. Importantly, no signs of clinical deterioration and right $\mathrm{HF}$ were detected during their hospitalization. No serious adverse episodes were recorded in between hospital discharge (at the end of a 3-week inhospital stay) and the planned follow-up (15 weeks later, upon completion of the home ET program). Some authors reported some sporadic complications that occurred during the $6 \mathrm{MWD}$ test, as the case of a patient developing ventricular tachycardia (77) and of a lady developing symptomatic bradycardia and hypoxia (78). No other studies reported significant side effects related to ET. In our clinical experience, all patients adhered to the ET plan without adverse events, and showed stable hemodynamics, as witnessed by stable levels of natriuretic peptides (57).

In conclusions, the available data indicate that ET in $\mathrm{PAH}$ is mostly safe, although it may not be completely harmless. Therefore, besides a careful selection of patients to enroll, ET should be carefully supervised and closely monitored.

\section{How to choose patients to submit to ET}

Many preclinical studies on experimental models of the hypoxia or monocrotaline induced $\mathrm{PAH}$ in rats showed that a prior physical training exerted a cardioprotective effect on the RV heart when PAP progressively raises $(79,80)$. 
Unfortunately, PAH is often diagnosed at an advanced stage (WHO FC III-IV). At this point, the primary parameter determining the symptoms and prognosis of the patients is the cardiac reserve. The PVR together with the RV adaptation define this parameter. In fact, the main objection of ET detractors in PAH is that intense exercise may accelerate the deterioration of RV function (81).

During exercise, in severe PAH the right ventricle is forced to increase its output against a high resistance circuit. In addition, within the pulmonary circulation phenomena of adaptation to exercise, such as vasodilation and the recruitment of new capillaries are no longer possible. If stroke volume cannot rise, increasing HR remains the only chance to increase $\mathrm{CO}$ (82).

Thus, it becomes important to be able to discriminate those patients who can benefit from a more intensive training, reserving a more conservative treatment (mobilization in the bed, psychological support, breathing exercises) to patients with exhausted RV reserve. Indeed, it is the presence of a residual reserve that can determine the response to ET (2) as well demonstrated in laboratory animals affected by PAH. In PAH rats with preserved CO, ET was well tolerated and markedly increased exercise endurance with a significant increase of capillary density in cardiomyocytes. Conversely, in rats with progressive $\mathrm{PAH}$ and reduced RV reserve, ET increased pulmonary vascular remodeling and worsened survival (83).

Therefore, it seems important to assess the baseline $\mathrm{RV}$ function, and in particular whether the RV contractile reserve is partially preserved. In this perspective, besides the diagnostic role, echocardiography is an important and accurate prognostic tool. The RV Tei myocardial index, i.e., the sum of isovolumetric contraction and relaxation time interval, divided by ejection time, is a good marker of both RV function and prognosis. An increased Tei index is associated with a major RV dysfunction. Tei index is minimally affected by RV geometry, tricuspid regurgitation (TR), or RV filling state, furthermore it is reproducible and easy to calculate (84).

The best mean of assessing RV afterload during exercise is by quantifying the relationship between PAP and $\mathrm{CO}$, the so-called pressure/flow (P/Q) relationship (85), which can be performed using invasive measures, noninvasive surrogates, or even exercise cardiac MRI (86). These relationships have the potential to identify subclinical pulmonary vascular pathological conditions and to explain exercise tolerance. Assessment of contractile reserve is also critical. If the right heart fails to meet the contractile requirements of the increased afterload during exercise, it will fail to increase RV pressures, PAP and CO, whereby a failure to increase PAP is associated with poor exercise capacity and poor prognosis. Thus, the combined assessment of the P/Q relationship and RV function during exercise provides an excellent opportunity to explain patients' symptoms, prognosis, and response to therapy.

Considering that the exercise-induced PASP is a measure of RV contractile reserve, PASP changes have been evaluated during CPET in PAH patients. Although echocardiographic parameters, such as right heart volumes, were not significantly different, a PASP increase $>30 \mathrm{mmHg}$ during exercise was an independent prognostic marker (87).

Echocardiography represents an excellent non-invasive tool to verify the adaptation of the pulmonary circulation and the right heart during exercise in patients with PAH. Exercise echocardiography for $\mathrm{PH}$ focuses on calculation of CO and PASP (88), rather than LV wall motion abnormalities. In addition, contrast-enhanced signals by agitated saline infusion may improve the rate of measurable TR jet velocity at rest from $56 \%$ to $92 \%$ and during exercise from $39 \%$ to $89 \%$ (89). However, we must acknowledge that so far no validated Doppler-echocardiographic markers of $\mathrm{RV}$ response to exercise are available. Further studies should address this issue, in particular to discriminate patients at high risk for exercise complications.

All these data confirm the importance to diagnose $\mathrm{PAH}$ at an early stage, in order to improve the response to therapy and ET, increasing the survival and decreasing the morbidity. With the aim to act when the FC is not yet deteriorated, we should try to assess the functional status of our patients in the most objective way, as by CPET (90) or exercise echocardiography.

\section{Economical sustainability of rehabilitation programs in PAH}

The economic burden of patients with PAH is noteworthy. Doubtless, the cost for drugs represents the main determinant of the whole expenditure, although the indirect costs for the treatment of patients with PAH are not clearly defined, as suggested by recent surveys $(91,92)$. These reviews showed that the health care costs for treating $\mathrm{PAH}$ in USA varied widely from $2,476 \$$ to $11,875 \$$ per patient per month.

In Germany, the average annual cost for the treatment of $\mathrm{PAH}$ has been evaluated to range from $48,000 €$ up to $110,000 €$ per patient. The worsening of WHO FC and/ 
or the occurrence of new clinical events may determine a further increase of the costs due to hospital admissions and a greater use of combination therapies (12). In this scenario, it would be important to define a targeted rehabilitation plan that might restrain the health care costs, as it has already been demonstrated in chronic HF (93).

The REVEAL reported that over 1 year, the time free from hospitalization ranged from $67 \%$ in PAH secondary to connective tissue diseases to $73 \%$ in idiopathic forms (64).

Ehlken et al. (12) evaluated the effect of training on morbidity and mortality of $58 \mathrm{PAH}$ patients compared with a retrospective control group of 48 patients treated with usual care. During the follow-up, only $25.8 \%$ of the patients enrolled in the ET had adverse events, a rate much lower when compared to the control patients, who had adverse events in $54.4 \%$ of the cases (12). The 1- and 2-year survival rates were higher in the training group compared to the controls (100\% and $95 \%$ vs. $93 \%$ and $88 \%$, respectively; $\mathrm{P}<0.05)$. The ET group had also lower incidence of clinical worsening $(\mathrm{P}<0.005)$.

Consequently, lower incidence of adverse events may carry to a reduction of healthcare expenditures in the whole population of $\mathrm{PAH}$ patients. Moreover, together with the advantages related to ET, a higher patient's awareness and ability to self-manage may have a beneficial effect on the healthcare costs.

Even with the limitations of a retrospective comparison, Ehlken et al. demonstrated that in a follow-up period of 2 years there was a $657 € /$ year saving in the ET group, due to the reduced need of additional PAH specific medications (12).

In some countries, for example in Germany, the importance of the rehabilitation program in patients affected by PAH is largely recognized, so that the cost of rehabilitation admission is completely covered by the health insurance companies. In other countries, for example in Italy, where the cost of the admission to the rehabilitation program is mainly covered by the public health system, the length of the in-hospital stay and the cost of related drugs of the PAH patients are usually submitted to a careful evaluation by the budgetary national and local authorities of the public spending.

Some studies documented the possibility to administer ET to patients in stable clinical conditions in an outpatient regimen leading to an additional beneficial effect on the overall expenditure $(57,94,95)$. Importantly, these studies demonstrated that no meaningful increase of adverse events and side effects occurred in these patients; however, we strongly believe that a careful monitoring of the patients eligible to the ambulatory training should be always implemented. Conversely, when there is evidence of recent (<3 months) clinical instability, an inpatient rehabilitation program should be recommended.

\section{Conclusions}

Studies agree on the favorable effects of training programs on functional capacity and QoL of patients affected by PAH. Some preliminary observations would even suggest an improvement in terms of survival. Several issues related to the feasibility of the in-hospital rehabilitation programs need to be clarified, in particular the organizational, cultural and above all economic issues necessitate of additional data and debate. Home-based training could also be a suitable option, in particular in those countries where there is no private insurance or public health support.

Larger clinical trials with a long-term follow-up are needed to define the dose-response relationship and to determine more precisely its impact on patients' functional capacity, cardiovascular performance QoL and survival. It would be worthwhile to explore the impact of a more extensive program of training in this population. On the other side, the assessment of the effects of exercise on pulmonary circulation, cellular and inflammatory pathways, and cardiovascular neural regulation in $\mathrm{PAH}$ should be the aim of next trials.

In conclusion, ET appears to be a promising adjunctive intervention to drug therapies, near to be accepted as an integral component of the evidence-based recommendations for managing patients with PAH.

"Meanwhile, there is evidence enough to dream and hope for a day when there might be a special Olympics for our PAH patients" (96).

\section{Acknowledgements}

We would like to thank our patients, who always encourage our work. Their friendship, trust, and effort are precious to us.

\section{Footnote}

Conflicts of Interest: The authors have no conflicts of interest to declare.

\section{References}

1. Hoeper MM, Bogaard HJ, Condliffe R, et al. Definitions 
and diagnosis of pulmonary hypertension. J Am Coll Cardiol 2013;62:D42-D50.

2. La Gerche A, Claessen G. Is exercise good for the right ventricle? Concepts for health and disease. Can J Cardiol 2015;31:502-8.

3. Simonneau G, Galié N, Rubin LJ, et al. Clinical classification of pulmonary hypertension. J Am Coll Cardiol 2004;43: 5S-12S.

4. Grünig E, Ehlken N, Ghofrani A, et al. Effect of exercise and respiratory training on clinical progression and survival in patients with severe chronic pulmonary hypertension. Respiration 2011;81:394-401.

5. Grünig E, Maier F, Ehlken N, et al. Exercise training in pulmonary arterial hypertension associated with connective tissue diseases. Arthritis Res Ther 2012;14:R148.

6. Hoeper MM, Markevych I, Spiekerkoetter E, et al. Goaloriented treatment and combination therapy for pulmonary arterial hypertension. Eur Respir J 2005;26:858-63.

7. McLaughlin VV, Shillington A, Rich S. Survival in primary pulmonary hypertension: the impact of epoprostenol therapy. Circulation 2002;106:1477-82.

8. Nagel C, Prange F, Guth S, et al. Exercise training improves exercise capacity and quality of life in patients with inoperable or residual chronic thromboembolic pulmonary hypertension. PLoS One 2012;7:e41603.

9. Sitbon O, McLaughlin VV, Badesch DB, et al. Survival in patients with class III idiopathic pulmonary arterial hypertension treated with first line oral bosentan compared with an historical cohort of patients started on intravenous epoprostenol. Thorax 2005;60:1025-30.

10. Mereles D, Ehlken N, Kreuscher S, et al. Exercise and respiratory training improve exercise capacity and quality of life in patients with severe chronic pulmonary hypertension. Circulation 2006;114:1482-9.

11. Becker-Grünig T, Klose H, Ehlken N, et al. Efficacy of exercise training in pulmonary arterial hypertension associated with congenital heart disease. Int J Cardiol 2013;168:375-81.

12. Ehlken N, Verduyn C, Tiede H, et al. Economic evaluation of exercise training in patients with pulmonary hypertension. Lung 2014;192:359-66.

13. Grünig E, Lichtblau M, Ehlken N, et al. Safety and efficacy of exercise training in various forms of pulmonary hypertension. Eur Respir J 2012;40:84-92.

14. Kabitz HJ, Bremer HC, Schwoerer A, et al. The combination of exercise and respiratory training improves respiratory muscle function in pulmonary hypertension. Lung 2014;192:321-8.
15. de Man FS, Handoko ML, Groepenhoff H, et al. Effects of exercise training in patients with idiopathic pulmonary arterial hypertension. Eur Respir J 2009;34:669-75.

16. Ehlken N, Lichtblau M, Klose H, et al. Exercise training improves peak oxygen consumption and haemodynamics in patients with severe pulmonary arterial hypertension and inoperable chronic thrombo-embolic pulmonary hypertension: a prospective, randomized, controlled trial. Eur Heart J 2016;37:35-44.

17. Galiè N, Corris PA, Frost A, et al. Updated treatment algorithm of pulmonary arterial hypertension. JACC 2013;62:D60-72.

18. Chan L, Chin LM, Kennedy M, et al. Benefits of intensive treadmill exercise training on cardiorespiratory function and quality of life in patients with pulmonary hypertension. Chest 2013;143:333-43.

19. Weinstein AA, Chin LM, Keyser RE, et al. Effect of aerobic exercise training on fatigue and physical activity in patients with pulmonary arterial hypertension. Respir Med 2013;107:778-84.

20. Meyer FJ, Lossnitzer D, Kristen AV, et al. Respiratory muscle dysfunction in idiopathic pulmonary arterial hypertension. Eur Respir J 2005;25:125-30.

21. Kabitz HJ, Schwoerer A, Bremer HC, et al. Impairment of respiratory muscle function in pulmonary hypertension. Clinical Science 2008;114:165-71.

22. Naeije R, Chesler N. Pulmonary circulation at exercise. Compr Physiol 2012;2:711-41.

23. Marra AM, Arcopinto M, Bossone E, et al. Pulmonary arterial hypertension-related myopathy: an overview of current data and future perspectives. Nutr Metab Cardiovasc Dis 2015;25:131-9.

24. Hoeper MM, Pletz MW, Golpon H, et al. Prognostic value of blood gas analyses in patients with idiopathic pulmonary arterial hypertension. Eur Respir J 2007;29:944-50.

25. Reid MB, Lannergren J, Westerblad H. Respiratory and limb muscle weakness induced by tumor necrosis factoralpha: involvement of muscle myofilaments. Am J Respir Crit Care Med 2002;166:479-84.

26. Li YP, Chen Y, John J, et al. TNF-alpha acts via p38 MAPK to stimulate expression of the ubiquitin ligase atrogin $1 / \mathrm{MAFbx}$ in skeletal muscle. FASEB J 2005;19:362-70.

27. Hassoun PM, Mouthon L, Barberà JA, et al. Inflammation, growth factors, and pulmonary vascular remodeling. J Am Coll Cardiol 2009;54:S10-S19.

28. Soon E, Holmes AM, Treacy CM, et al. Elevated levels of inflammatory cytokines predict survival in idiopathic 
and familial pulmonary arterial hypertension. Circulation 2010;122:920-7.

29. Späte U, Schulze PC. Proinflammatory cytokines and skeletal muscle. Curr Opin Clin Nutr Metab Care 2004;7:265-9.

30. Hansmann G, Wagner RA, Schellong S, et al. Pulmonary arterial hypertension is linked to insulin resistance and reversed by peroxisome proliferator-activated receptorgamma activation. Circulation 2007;115:1275-84.

31. Franssen FM, Wouters EF, Schols AM. The contribution of starvation, deconditioning and ageing to the observed alterations in peripheral skeletal muscle in chronic organ diseases. Clin Nutr 2002;21:1-14.

32. Dimopoulos S, Tzanis G, Manetos C, et al. Peripheral muscle microcirculatory alterations in patients with pulmonary arterial hypertension: a pilot study. Respir Care 2013;58:2134-41.

33. Barbosa PB, Ferreira EM, Arakaki JS, et al. Kinetics of skeletal muscle $\mathrm{O} 2$ delivery and utilization at the onset of heavy-intensity exercise in pulmonary arterial hypertension. Eur J Appl Physiol 2011;111:1851-61.

34. Mainguy V, Maltais F, Saey D, et al. Peripheral muscle dysfunction in idiopathic pulmonary arterial hypertension. Thorax 2010;65:113-7.

35. de Man FS, Van Hees HW, Handoko ML, et al. Diaphragm muscle fiber weakness in pulmonary hypertension. Am J Respir Crit Care Med 2011;183:1411-8.

36. Manders E, De Man FS, Handoko ML, et al. Diaphragm weakness in pulmonary arterial hypertension: role of sarcomeric dysfunction. Am J Physiol Lung Cell Mol Physiol 2012;303:L1070-8.

37. Clark AL, Piepoli M, Coats AJ. Skeletal muscle and the control of ventilation on exercise: evidence for metabolic receptors. Eur J Clin Invest 1995;25:299-305.

38. Triposkiadis F, Karayannis G, Giamouzis G, et al. The sympathetic nervous system in heart failure physiology, pathophysiology, and clinical implications. J Am Coll Cardiol 2009;54:1747-62.

39. Pinna GD, Porta A, Maestri R, et al. Different estimation methods of spontaneous baroreflex sensitivity have different predictive value in heart failure patients. J Hypertens 2017;35:1666-75.

40. Dimopoulos S, Anastasiou-Nana M, Katsaros F, et al. Impairment of autonomic nervous system activity in patients with pulmonary arterial hypertension: a case control study. J Card Fail 2009;15:882-9.

41. Galiè N, Humbert M, Vachiery JL, et al. Guidelines for the diagnosis and treatment of pulmonary hypertension. The task force for the diagnosis and treatment of pulmonary hypertension of the European Society of Cardiology (ESC) and the European Respiratory Society (ERS). Endorsed by: Association for Paedriatic and Congenital Cardiology (AEPC), International Society of Heart and Lung Transplantation (ISHLT). Eur Heart J 2016;37:67-119.

42. Colombo R, Siqueira R, Conzatti A, et al. Exercise training contributes to $\mathrm{H} 2 \mathrm{O} 2 / \mathrm{VEGF}$ signaling in the lung of rats with monocrotaline-induced pulmonary hypertension. Vascul Pharmacol 2016;87:49-59.

43. Kawanishi N, Yano H, Yokogawa Y, et al. Exercise training inhibits inflammation in adipose tissue via both suppression of macrophage infiltration and acceleration of phenotypic switching from M1 to M2 macrophages in high-fat-diet-induced obese mice. Exerc Immunol Rev 2010;16:105-18.

44. Jaenisch RB, Quagliotto E, Chechi C, et al. Respiratory Muscle Training Improves Chemoreflex Response, Heart Rate Variability, and Respiratory Mechanics in Rats With Heart Failure. Can J Cardiol 2017;33:508-14.

45. Dalla Vecchia L, Mangini A, Di Biasi P, et al. Improvement of left ventricular function and cardiovascular neural control after endoventriculoplasty and myocardial revascularization. Cardiovasc Res 1998;37:101-7.

46. Gademan MG, Swenne CA, Verwey HF, et al. Effect of exercise training on autonomic derangement and neurohumoral activation in chronic heart failure. J Card Fail 2007;13:294-303.

47. Coats AJS, Adamopoulos S, Radaelli A, et al. Controlled trial of physical training in chronic heart failure: exercise performance, hemodynamics, ventilation and autonomic function. Circulation 1992;85:2119-31.

48. Shoemaker MJ, Wilt JL, Dasgupta R, et al. Exercise training in patients with pulmonary arterial hypertension: a case report. Cardiopulm Phys Ther J 2009;20:12-8.

49. Ley S, Fink C, Risse F, et al. Magnetic resonance imaging to assess the effect of exercise training on pulmonary perfusion and blood flow in patients with pulmonary hypertension. Eur Radiol 2013;23:324-31.

50. Meyer K, Samek L, Schwaibold M, et al. Physical responses to different modes of interval exercise in patients with chronic heart failure - application to exercise training. Eur Heart J 1996;17:1040-7.

51. Meyer K, Samek L, Schwaibold M, et al. Interval training in patients with severe chronic heart failure: analysis and recommendations for exercise procedures. Med Sci Sports 
Exerc 1997;29:306-12.

52. Goldstein RS, Gort EH, Stubbing D, et al. Randomised controlled trial of respiratory rehabilitation. Lancet 1994;344:1394-7.

53. Ries AL, Bauldoff GS, Carlin BW, et al. Pulmonary Rehabilitation: Joint ACCP/AACVPR Evidence-Based Clinical Practice Guidelines. Chest 2007:131:4S-42S.

54. Birnbaum S, Carlin B. Pulmonary rehabilitation and respiratory therapy services in the physician office setting. Chest 2006;129:169-73.

55. Feltz D, Landers D. The effects of mental practice on motor skill learning and performance: A meta-analysis. J Sport Psychol 1983;5:25-57.

56. Mayer J, Hermann H. Mentales Training - Grundlagen und Anwendung in Sport, Rehabilitation, Arbeit und Wirtschaft. Heidelberg: Springer Medizin Verlag, 2009.

57. Bussotti M, Gremigni P, Pedretti RFE, et al. Effects of an outpatient service rehabilitation programme in patients affected by pulmonary arterial hypertension: an observational study. Cardiovasc Hematol Disord Drug Targets 2017;17:3-10.

58. Bernardi L, Porta C, Spicuzza L, et al. Slow breathing increases arterial baroreflex sensitivity in patients with chronic heart failure. Circulation 2002;105:143-5.

59. Raupach T, Bahr F, Herrmann P, et al. Slow breathing reduces sympathoexcitation in COPD. Eur Respir J 2008;32:387-92.

60. Plentz RD, Sbruzzi G, Ribeiro RA, et al. Inspiratory muscle training in patients with heart failure: meta-analysis of randomized trials. Arq Bras Cardiol 2012;99:762-71.

61. Martínez-Quintana E, Miranda-Calderín G, UgarteLopetegui A, et al. Rehabilitation program in adult congenital heart disease patients with pulmonary hypertension. Congenit Heart Dis 2010;5:44-50.

62. Yuan P, Yuan XT, Sun XY, et al. Exercise training for pulmonary hypertension: a systematic review and metaanalysis. Int J Cardiol 2015;178:142-6.

63. Arena R, Cahalin ET, Borghi-Silva A, et al. The effect of exercise training on the pulmonary arterial system in patients with pulmonary hypertension. Prog Cardiovasc Dis 2015;57:480-8.

64. Barst RJ, Chung L, Zamanian RT, et al. Functional class improvement and 3-year survival outcomes in patients with pulmonary arterial hypertension in the REVEAL Registry. Chest 2013;144:160-8.

65. Chung L, Liu J, Parsons L, et al. Characterization of connective tissue disease-associated pulmonary arterial hypertension from REVEAL: identifying systemic sclerosis as a unique phenotype. Chest 2010;138:1383-94.

66. Piepoli MF, Hoes AW, Agewall S, et al. 2016 European Guidelines on cardiovascular disease prevention in clinical practice: The Sixth Joint Task Force of the European Society of Cardiology and Other Societies on Cardiovascular Disease Prevention in Clinical Practice (constituted by representatives of 10 societies and by invited experts). Developed with the special contribution of the European Association for Cardiovascular Prevention \& Rehabilitation (EACPR). Eur Heart J 2016;37:2315-81.

67. Ponikowski P, Voors AA, Anker SD, et al. 2016 ESC Guidelines for the diagnosis and treatment of acute and chronic heart failure: The Task Force for the diagnosis and treatment of acute and chronic heart failure of the European Society of Cardiology (ESC). Developed with the special contribution of the Heart Failure Association (HFA) of the ESC. Eur Heart J 2016;37:2129-200.

68. Besnier F, Labrunée M, Pathak A, et al. Exercise traininginduced modification in autonomic nervous system: An update for cardiac patients. Ann Phys Rehabil Med 2017;60:27-35.

69. Löwe B, Gräfe K, Ufer C, et al. Anxiety and depression in patients with pulmonary hypertension. Psychosom Med 2004;66:831-6.

70. Wryobeck JM, Lippo G, McLaughlin V, et al. Psychosocial aspects of pulmonary hypertension: a review. Psychosomatics 2007;48:467-75.

71. Badesch DB, Raskob GE, Elliott CG, et al. Pulmonary arterial hypertension: baseline characteristics from the REVEAL Registry. Chest 2010;137:376-87.

72. McCollister DH, Beutz M, McLaughlin V, et al. Depressive symptoms in pulmonary arterial hypertension: prevalence and association with functional status. Psychosomatics 2010;51:339.

73. Harzheim D, Klose H, Pinado FP, et al. Anxiety and depression disorders in patients with pulmonary arterial hypertension and chronic thromboembolic pulmonary hypertension. Respir Res 2013;14:104.

74. Cenedese E, Speich R, Dorschner L, et al. Measurement of quality of life in pulmonary hypertension and its significance. Eur Respir J 2006;28:808-15.

75. McKenna SP, Doughty N, Meads DM, et al. The Cambridge Pulmonary Hypertension Outcome Review (CAMPHOR): a measure of health-related quality of life and quality of life for patients with pulmonary hypertension. Qual Life Res 2006;15:103-15.

76. Mar PL, Nwazue V, Black BK, et al. Valsalva Maneuver in Pulmonary Arterial Hypertension: Susceptibility 
to Syncope and Autonomic Dysfunction. Chest 2016;149:1252-60.

77. Seale H, Harris J, Hall K, et al. The hidden risk of a 6-minute walk test in pulmonary arterial hypertension. Pulm Circ 2011; 1:S33-S8.

78. Babu AS, Padmakumar R, Maiya AG, et al. Effects of Exercise Training on Exercise Capacity in Pulmonary Arterial Hypertension: A Systematic Review of Clinical Trials. Heart Lung Circ 2016;25:333-41.

79. Moreira-Gonçalves D, Ferreira R, Fonseca H, et al. Cardioprotective effects of early and late aerobic exercise training in experimental pulmonary arterial hypertension. Basic Res Cardiol 2015;110:57.

80. Pacagnelli FL, De Almeida Sabela AK. Preventive aerobic training exerts a cardioprotective effect on rats treated with monocrotaline. Int J Exp Pathol 2016;97:238-47.

81. Spruijt OA, de Man FS, Groepenhoff H, et al. The effects of exercise on right ventricular contractility and right ventricular- arterial coupling in pulmonary hypertension. Am J Respir Crit Care Med 2015;191:1050-7.

82. Waxman AB. Exercise physiology and pulmonary arterial hypertension. Prog Cardiovasc Dis 2012;55:172-9.

83. Handoko ML, De Man FS, Happé CM, et al. Opposite effects of training in rats with stable and progressive pulmonary hypertension. Circulation 2009;120:42-9.

84. Vonk MC, Sander MH, van den Hoogen FH, et al. Right ventricle Tei-index: A tool to increase the accuracy of non-invasive detection of pulmonary arterial hypertension in connective tissue diseases. Eur J Echocardiogr 2007;8:317-21.

85. Lewis GD, Bossone E, Naeije R et al. Pulmonary vascular hemodynamic response to exercise in cardiopulmonary diseases. Circulation 2013;128:1470-9.

86. La Gerche A, Claessen G, Van de Bruaene A, et al. Cardiac MRI: a new gold standard for ventricular volume quantification during high-intensity exercise. Circ Cardiovasc Imaging 2013;6:329-38.

87. Grünig E, Tiede H, Enyimayew EO, et al. Assessment and prognostic relevance of right ventricular contractile reserve in patients with severe pulmonary hypertension. Circulation 2013;128:2005-15.

88. Bossone E, Rubenfire M, Bach DS, et al. Range of tricuspid regurgitation velocity at rest and during exercise in normal adult men: implications for the diagnosis of pulmonary hypertension. J Am Coll Cardiol 1999;33:1662-6.

89. Kuecherer HF, Will M, da Silva KG, et al. Contrast enhanced Doppler ultrasound for noninvasive assessment of pulmonary artery pressure during exercise in patients with chronic congestive heart failure. Am J Cardiol 1996;78:229-32.

90. Paolillo S, Farina S, Bussotti M, et al. Exercise testing in the clinical management of patients affected by pulmonary arterial hypertension. Eur J Prev Cardiol 2012;19:960-71.

91. Gu S, Hu H, Dong H. Systematic Review of the Economic Burden of Pulmonary Arterial Hypertension. Pharmacoeconomics 2016;34:533-50.

92. Sikirica M, Iorga SR, Bancroft T, et al. The economic burden of pulmonary arterial hypertension $(\mathrm{PAH})$ in the US on payers and patients. BMC Health Serv Res 2014;14:676.

93. Rauch B, Davos CH, Doherty P, et al. The prognostic effect of cardiac rehabilitation in the era of acute revascularisation and statin therapy: A systematic review and meta-analysis of randomized and non-randomized studies - The Cardiac Rehabilitation Outcome Study (CROS). Eur J Prev Cardiol 2016;23:1914-39.

94. Fox BD, Kassirer M, Weiss I, et al. Ambulatory rehabilitation improves exercise capacity in patients with pulmonary hypertension. J Card Fail 2011;17:196-200.

95. Inagaki T, Terada J, Tanabe N, et al. Home-based pulmonary rehabilitation in patients with inoperable or residual chronic thromboembolic pulmonary hypertension: a preliminary study. Respir Investig 2014;52:357-64.

96. Madonna R, De Caterina R, Geng YJ. Aerobic exerciserelated attenuation of arterial pulmonary hypertension: A right arrow targets the disease? Vascul Pharmacol 2016;87:6-9.
Cite this article as: Dalla Vecchia LA, Bussotti M. Exercise training in pulmonary arterial hypertension. J Thorac Dis 2018;10(1):508-521. doi:10.21037/jtd.2018.01.90 